\title{
Performance-Based Transit Operating Subsidy Allocation: A Before and After Study
}

\author{
Matthew G. Karlaftis \\ Kumares C. Sinha \\ Purdue University
}

\begin{abstract}
$\overline{\text { Abstract }}$
Transit operating subsidy allocation procedures based on such factors as deficit or population have been under attack ever since operating subsidy became widespread in the 1970s. These procedures do not directly provide any incentive for innovation, cost cutting strategies, and efficient operation. Recognizing the problems associated with a 100 percent population-based formula, the State of Indiana, since 1986, has used transit performance as a part of its subsidy allocation procedure. This paper examines the impact of this procedure on transit system self-reliance, efficiency, and effectiveness by analyzing the relevant data between the periods before and after the procedure was instituted. The results show that the procedure has positively affected transit system performance, particularly for small-and medium-sized properties. The largest positive change has been realized in transit system effectiveness and self-reliance, while no perceptible change was observed in transit system efficiency.
\end{abstract}

\section{Introduction}

Since the 1970s, government financial support for public transport operations grew at the same time that operating losses and investment needs for public 
transport increased. The total operating subsidy from all levels of government (local, state, and federal) rose from $\$ 318$ million in 1970 to $\$ 9268$ million in 1990, a near thirty-fold increase in 20 years (Pucher 1995). This tremendous increase in subsidies was justified by the prevailing philosophy of keeping fares below operating costs and maintaining and expanding services, regardless of their profitability (Cervero 1984). It was expected that transit would play a key role in achieving the following objectives:

- preserving and revitalizing the cities;

- creating a more efficient and less costly—in terms of energy—form of transport;

- creating a better urban environment, mainly in terms of traffic congestion and pollution;

- continuing the use of the existing public transport infrastructure;

- satisfying the transport needs of the "underprivileged" (the elderly, people with disabilities, people in remote areas, etc.); and

- helping "captive" users who might be paying an increasing amount of money for decreasing service (Altshuler 1981).

In general, subsidizing a commodity necessitates the diversion of resources away from other (more productive) uses; this becomes a strong argument against charging less than the true economic price of the commodity (i.e., subsidizing a commodity). Nevertheless, if one section of the traveling community (automobile users) is already paying less than the true costs of travel (when social costs are included), subsidizing public transportation may be one way of redressing the balance (Bly et al. 1980).

Unfortunately, the effects of operating subsidies on performance and productivity of transit systems have not been encouraging. Many authors contended that subsidies had encouraged productivity declines, lack of innovation and initiative, and financial mismanagement of transit properties. Arguments against subsidies appeared from the very beginning of the transit subsidization legislation (Meyer et al. 1965). Many authors also argued that the benefits from subsidies to transit riders were negligible relative to the levels of subsidies; they also 
proposed that the environmental and secondary financial benefits were nonexistent (Altshuler et al. 1981, Bonnell 1981, Meyer and Gomez-Ibanez 1981, Hilton 1974, Hammer 1976, U.S. House of Representatives 1981, Webber 1976).

In recent years, many studies have been performed using a large number of different methodological approaches to investigate empirically the effects of operating assistance on the performance of transit systems. Pucher, Markstedt and Hirschman (1983), Anderson (1983), Cervero (1984, 1986), Pickrell (1985), and Bly and Oldfield (1986) used different multiple regression models to quantify the effects of subsidies. While the specific results varied among the studies, it was concluded that there are clear links between increases in subsidies, on one hand, and reductions in performance and productivity, on the other. Moreover, as Bly and Oldfield (1986) reported, "the time-lagged regression suggested that, to some extent, the increases in cost followed, rather than preceded, the increases in subsidy. ... This leaves the suspicion that subsidy may have encouraged a loss of efficiency." Recently, Obeng, Talley and Colburn (1995), using a translog cost function, found that transit costs were positively related to transit subsidies; that is, increases in subsidies were related to increases in transit operating costs.

To deal with the reality of the negative influence of subsidies on the performance of transit systems, many authors suggested that a performance-based allocation formula be used in subsidizing public transit (Lamare 1980, Miller 1980, Crider and Sinha 1982, Pucher and Markstedt 1983, Pucher, Markstedt and Hirschman 1983, Pucher 1995). Such a formula would reward those systems that raise productivity, attract new passengers, and enhance operating efficiency. Indeed, proposals were made for the implementation of various approaches of performance-based state transit subsidy allocation programs in California (in 1971), Pennsylvanía (in 1978), New York (in 1979), Iowa (in 1982), and Indiana (in 1985). A survey of the different states' subsidy allocation procedures as of the early 1980 s can be found in Sinha et al. (1985).

This paper seeks to examine the effects of the performance-based subsidy allocation procedure on the performance of Indiana transit systems. Using data from all the fixed-schedule, fixed-route transit systems in Indiana for an 18-year 
period (1977-1994), this paper investigates whether there was a significant change in the performance of the transit systems between the pre- and the post-performance-based subsidy allocation periods. The paper is organized as follows: the first section describes the operating subsidy allocation procedure implemented in Indiana in 1986; the second section describes the data and the analysis methodology; the third section interprets the results obtained from the study; and the last section summarizes the findings of this study.

\section{The Subsidy Allocation Procedure}

\section{Federal and State Practices}

Until June 1985, Indiana's state subsidy allocation procedure followed the population-based federal allocation formula. From 1974 through 1985, the amount of federal operating assistance that could be obtained under Section 5 was primarily based on population and population density factors. That is, the National Mass Transportation Act of 1974 allocated funds based half on the recipient's population as a percentage of total eligible population and half on the percentage of the total of the recipient's population density multiplied by the population. At the federal level, the application of such an allocation procedure presented several weaknesses that needed to be addressed. First, the supply of federal funds was not optimally matched with each area's relative use of urban mass transit. While the formula attempted to distribute the assistance equitably by using the population/population density formula and by setting aside funds for the largest areas, federal support per passenger, per vehicle mile, and as a percentage of expenses became much higher in some areas than others. Second, deficits were rewarded. Because federal operating assistance was limited to 50 percent of a system's deficit, the larger the deficit, the more funds could be received. Finally, the allocation procedure provided no incentive for systems to improve operational efficiency and to attain federal transit goals.

There is little overall uniformity among the states in methods used to allocate state transit funds. The Public Mass Transportation Fund (PMTF, Indiana's state subsidy program) is a special revenue fund created by the 1980 Indiana General Assembly to assist public transportation in the state. According to stat- 
ute, funds in the PMTF are to be used solely for the promotion and development of public mass transportation. The PMTF evolved from a state grant program established in 1975. Part of the program called for annual general fund appropriations designed to assist local units of government in matching public transportation grants provided under the Federal Urban Mass Transportation Act of 1964. It was strictly a matching grant program to augment local matching funds at a time when municipal corporations were under financial constraints imposed by the property tax control program.

In creating the PMTF, the General Assembly changed the funding source from a general funds appropriation to a dedicated 0.76 percent of the state's 5 percent general sales and use tax. In addition to creating a dedicated source of funds, the General Assembly also increased the state's participation in the local share of a federal grant from one-half to two-thirds. The PMTF was originally set at 0.95 percent of the 4 percent general sales and use tax. The PMTF allows any municipal corporation that receives a federal mass transit grant to apply for state assistance. Until July 1985, the Indiana Department of Transportation (INDOT) made PMTF allocations based on the grant recipient's service area population. Service area population included the population within the municipal corporation's taxing unit or urbanized area as defined by the U.S. Census Bureau in the decennial census.

When the subsidy program began in 1975 , service area population seemed to be the only generally agreed-upon basis to allocate state funds. However, the INDOT found that the primary attribute of the population factor-that of stability-was also its major drawback. In using a 100 percent population-based formula, the INDOT was unable to respond to changes in the operation and financing of local transit service. Recognizing this disadvantage, a study was undertaken to examine alternative strategies (Sinha et al. 1984). The first step in this study was to establish the objectives involved in transit fund allocation, which were identified as sustenance, incentive, and innovation. Sustenance implies that transit systems remain in operation through adequate funding. Incentive aspects are intended to motivate a system to perform at a higher level than a given mini- 
mum service standard. Innovation is intended to encourage a system to try new concepts and ideas to improve service and control cost.

\section{Incorporation of Performance Indicators in}

\section{Transit Subsidy Allocation Procedure in Indiana}

The primary objective was to find a way to optimally allocate the limited resources available to accomplish as closely as possible the stated objectives. The new subsidy allocation procedure should motivate transit systems to control cost and improve service while encouraging them to seek out new sources of funding from the private sector. Those systems that strive to improve productivity and provide innovative services or pursue innovative financing schemes should be given proper credit in terms of fund allocation (Sinha et al. 1985).

In consultation with the transit operators and INDOT personnel, it was decided that the factors that would be included in the allocation procedure should be fair, equitable, and auditable. Most performance indicators that met the criteria mentioned above were considered. (Extensive analysis of transit system performance definition and measurement has been done by Fielding et al. [1978]). Many performance indicators represent similar attributes, and the selection of one eliminated the others. Some other indicators required data that were not reported by the Indiana systems. Finally, those indicators that best capture the state subsidy allocation goals were selected. After a series of intensive discussions with operators and transit board members, it was decided that the following three performance indicators would provide the basis for the allocation procedure:

- Operating Ratio: computed as the ratio of locally-derived income (LDI) over operating expense. LDI includes operating revenue, local subsidy, and private contributions. This indicator was used to capture the self sufficiency of a system along with the local commitment to the provision of transit service.

- Passengers per Capita (PC): used to capture the degree to which the residents in a particular area patronize their transit service. Also, it is an indicator of the reliability and service effectiveness.

- Passengers per Revenue Vehicle Mile (RPVM): measures service utili- 
zation. It also represents the effectiveness of the operation as it indicates passenger utilization throughout the system.

The necessary data for the computation of these indicators is either directly auditable (operating revenue and expense data) or can be readily checked on the basis of historical records, on-site inspection, and by cross checking with other financial data. To account for the wide diversity in the transit systems in Indiana, ranging from fairly large metropolitan systems to rural countywide systems, and capture the differences in operating characteristics, the systems were clustered in four groups: large, medium, small, and demand-responsive. Table 1 includes some of the characteristics of the first three groups.

The formula that was selected for allocating the state subsidy in Indiana is a four step process (Sinha et al. 1985):

TABLE 1

Characteristics of the Different System Categories (1994)

\begin{tabular}{|c|c|c|c|c|c|c|}
\hline \multirow[b]{2}{*}{ Characteristic } & \multicolumn{2}{|c|}{ Large } & \multicolumn{2}{|c|}{ Medium } & \multicolumn{2}{|c|}{ Small } \\
\hline & Mean & $\begin{array}{l}\text { Std. } \\
\text { Dev. }\end{array}$ & Mean & $\begin{array}{l}\text { Std. } \\
\text { Dev. }\end{array}$ & Mean & $\begin{array}{l}\text { Std. } \\
\text { Dev. }\end{array}$ \\
\hline \# of Systems & 4 & - & 8 & - & 9 & - \\
\hline \multicolumn{7}{|l|}{ Service Area } \\
\hline Population & 503,954 & 193,429 & 81,253 & 30,658 & 27,279 & 8,723 \\
\hline Total Vehicles & 135 & 118 & 30 & 15 & 9 & $\overline{4}$ \\
\hline Full-time & & $\because$ & & & & \\
\hline Employees & 265 & 244 & 47 & 18 & 12 & 6 \\
\hline Tot. Vehicle Miles & $3,111,719$ & $1,329,266$ & 824,860 & 385,922 & 180,031 & 99,775 \\
\hline Passengers - & $5,171,486$ & $1,481,231$ & 991,031 & 521,241 & 140,927 & 95,165 \\
\hline State Subsidy (\$) & $2,064,430$ & 508,715 & 307,663 & 155,194 & 88,646 & 32,559 \\
\hline $\begin{array}{l}\text { \% State Subsidy } \\
\text { of Total Subsidy }\end{array}$ & 19.6 & 3.1 & 25.8 & 2.6 & 29.1 & 2.4 \\
\hline $\begin{array}{l}\% \text { of System Deficit } \\
\text { Covered by PMTF }\end{array}$ & 11.0 & 2.1 & $13.3^{4}$ & 3.2 & 18.4 & 3.3 \\
\hline
\end{tabular}


1. Distribute 50 percent of the total available PMTF directly to each transit system according to the service area population of each system to satisfy the sustenance requirements.

2. Divide the remaining 50 percent of the funds into four amounts according to the subsidy needs of each group (i.e., large, medium, small, and demand-responsive) in relation to the total statewide subsidy requirement, as follows:

Group Allocation $=0.5 \times$ PMTF $\times$ (Group deficit/Total statewide deficit)

3. Suballocate each group amount among systems within the group in proportion to the following three factors:

$$
\begin{aligned}
& \frac{O R^{*} L D I}{\sum_{n}\left(O R^{*} L D I\right)} \\
& \frac{P C^{*} L D I}{\sum_{n}\left(P C^{*} L D I\right)} \\
& \frac{R P V M^{*} L D I}{\sum_{n}\left(R P V M^{*} L D I\right)}
\end{aligned}
$$

where,

$O R=$ Operating ratio $=\mathrm{LDI} /$ Operating expense

$L D I=$ Locally-derived income $=$ farebox and other direct revenue + local subsidy + private contribution

$P C \quad=$ Passenger trips per capita of service area population $R P V M=$ Passenger trips per revenue vehicle mile of operation $n=$ number of systems in a particular group

4. The total allocation to a system is the summation of the amount derived in Step 1 in addition to the amount obtained in Step 3. It should be noted 
that the amount of state subsidy for a given year is based on the performance indicators of the previous year. This suggests that there is a oneyear lag between the data year and the allocation year (for example, 1994 data are used in allocating funds for 1995).

This performance-based state subsidy allocation procedure was adopted by the State of Indiana in 1985, and 1986 was the first year in which the state subsidy was allocated based on this procedure. Transit operators were generally in support of the change, as there was now an accountable procedure that could connect subsidies with actions under their control. There were, however, some occasional complaints about the performance-based formula, particularly in relation to the group allocation of subsidies and the high weight assigned to LDI. Thus, although the formula was found to be sufficiently equitable and satisfactory to the transit operators during its existence over the past decade, the INDOT is currently reviewing the subsidy allocation procedure for possible modifications.

It is important to note the sensitivity of the allocation formula to the various performance measures used to allocate the available state funds. The formula places a high weight on local financial contribution which, based on the opinions of both Indiana transit operators and the INDOT, is the most important factor with respect to transit investment activities. To this end, innovative financing and local financial contribution to transit is rewarded highly by the existing formula. For example, in Muncie, a special taxing district, the Public Transit Corporation (PTC), was formed. The PTC, which allocates a proportion of the Muncie property tax for local transit support, raises approximately $\$ 2.2$ million in LDI annually. Terre Haute, on the other hand, which has neither established a PTC nor found any other innovative sources of financing or local contribution, raises only $\$ 350,000$ in LDI annually. As a result, and based on the allocation formula, Muncie receives approximately $\$ 785,000$ in state subsidy, while Terre Haute receives approximately $\$ 250,000$ in state subsidy. As noted by TCRP (1994), "The [Indiana state subsidy] allocation formula reflects-quite clearly what Indiana considers to be important with respect to its transit activities." 
The next section examines the impact of this procedure and estimates whether there was a change in the LDhand the performance indicators (OR, PC, RPVM) of the large, medium, and small systems as a result of this subsidy allocation procedure in the past nine years.

\section{Data Analysis}

The aim of the analysis was to examine the statistical relationship of the average values of LDI and the performance indicators between the period before and after the performance-based subsidy allocation procedure was instituted. This analysis uses the ANOVA method to compare the means of LDI and of the three indicators for the different periods and to establish whether there is a statistically significant difference in the means (between the periods). If the means differ between the periods, this could lead to the conclusion that performance-based subsidy allocation has had a significant effect on the performance of the systems.

The available data spanned a period of 18 years (1977-1994). The financial data were discounted using the Public Transportation deflator of the Consumer Price Index (CPI) to 1985 dollars and then subdivided into three subgroups: 1977 1985 , which is the period before the performance-based subsidy allocation procedure was instituted (Pre); 1986-1990, which is the first period after the procedure was instituted (Post 1); 1991-1994, which is the second period after the procedure was instituted (Post2). The data were subdivided into these three groupings rather than two (Pre and Post) to enable us to examine whether the performance-based subsidy allocation had an immediate impact on the systems (by comparing Pre to Post 1), or whether the systems took some time to adjust to the new procedure (by comparing Post1 to Post 2). ANOVA was applied separately to the three categories of systems; that is, the large, medium, and small systems were examined separately.

The first step in the analysis was to use ANOVA to verify the a priori hypothesis that the mean values of the three indicators for the three classes of systems are different (Table 2 gives the average values for LDI and for the three performance indicators for the three categories of systems). Table 3 shows the results for the ANOVA, testing the null hypothesis that the average values of the 


\begin{tabular}{|c|c|c|c|c|c|c|}
\hline \multirow[b]{3}{*}{ Indicator } & \multicolumn{6}{|c|}{$\begin{array}{l}\text { Table } 2 \\
\begin{array}{l}\text { Descriptive Statistics for the Three Performance Indicators } \\
\text { and LDI (1977-1994) }\end{array}\end{array}$} \\
\hline & \multicolumn{2}{|c|}{ Large Systems } & \multicolumn{2}{|c|}{ Medium Systems } & \multicolumn{2}{|c|}{ Small Systems } \\
\hline & Mean & Dev. & Mean & Dev. & Mean & Dev. \\
\hline LDI $(\$)$ & $5,456,394$ & $1,493,932$ & 595,227 & 311,335 & 102,749 & 81,423 \\
\hline OR & 0.4518 & 0.09 & 0.3528 & 0.11 & 0.4105 & 0.22 \\
\hline PC & 13.67 & 5.68 & 12.73 & 2.59 & 6.33 & 2.02 \\
\hline RPVM & 1.39 & 0.48 & 0.9 & 0.3 & 0.71 & 0.25 \\
\hline
\end{tabular}

three indicator means for the three system classes for the 1977-1994 period are equal. The value of the F-statistic indicates that the null hypothesis can be rejected, leading to the conclusion that the values of the performance indicators for the three categories of systems are indeed significantly different.

It is worth noting that the conclusions of the present research have been drawn based on the assumption that state subsidy is the only item affecting performance. Transit systems are regulated monopolies which, in allocating their resources, respond to specific regulatory constraints as well as to the level and composition of the market demand they face. It is thus likely that there exist other factors that also affect transit performance. Labor costs and form of ownership (public or private) are among the most important factors. Orski (1985) found that the effects of demand peaks on fleet size and the expansion of services to low density suburban areas are contributors to cost escalation and decline in transit productivity. Caves and Christensen (1988) found that speed, size of network, and average trip length have significant effects on performance. However, these factors have not significantly changed for the Indiana systems during the period of this study. The results reported here have examined the effect on transit system performance from the change in state subsidy allocation procedure for Indiana, ceteris paribus. 


\section{Table 3}

ANOVA Table for Compałring Indicator Means for Different System Sizes

\begin{tabular}{lccrccc} 
Indicator & Source & $\begin{array}{c}\text { Sum of } \\
\text { Squares }\end{array}$ & $d f$ & $\begin{array}{c}\text { Mean } \\
\text { Square }\end{array}$ & $\boldsymbol{F}$ & p-value \\
\hline OR & Size (model) & 0.535968 & 2 & 0.2679 & $10.55^{\mathrm{a}}$ & 0.0001 \\
& Error & 7.241606 & 285 & 0.0254 & & \\
& Total & 7.777574 & 287 & & & \\
& & & & & & \\
PC & Size (model) & 9019.4 & 2 & 4509.7 & $208.2^{\mathrm{a}}$ & 0.0001 \\
& Error & 6173.3 & 285 & 21.66 & & \\
& Total & 15192.7 & 287 & & & \\
RPVM & & & & & & \\
& Size (model) & 57.87 & 2 & 28.93 & $212.3^{\mathrm{a}}$ & 0.0001 \\
& Error & 38.84 & 285 & 0.13 & & \\
& Total & 96.71 & 287 & & &
\end{tabular}

a statistically significant at the $95 \%$ level

The OR (operating ratio) was the first measure to be examined (Figure 1 shows the trends in OR for the different classes of systems). The first step of the analysis examined whether there is significant difference in the OR of the three categories of systems between the Pre and the Post 1 periods. From Table 4 it can be inferred that there was a statistically-significant difference in the OR values between these periods for the large and the small systems (in both cases, the OR decreased in the Post 1 period). Then, the difference in OR was examined for the Post 1 and the Post 2 periods. The analysis leads to the conclusion that the OR values for the medium and small systems increased in the Post 2 period, while they were not significantly different between these two periods for the large systems.

Then, the passengers per capita were examined (Figure 2). In the Pre-Post 1 comparison, it was determined that there was a significant difference between the mean indicator values for the large and small systems; for both the large and 
Table 4

ANOVA Table for Comparing Indicator and LDI Means, by Period

\begin{tabular}{|c|c|c|c|c|c|c|c|c|c|c|}
\hline \multirow[b]{2}{*}{ Indicator } & \multirow[b]{2}{*}{ Period } & \multicolumn{3}{|c|}{ Large Systems } & \multicolumn{3}{|c|}{ Medium Systems } & \multicolumn{3}{|c|}{ Small Systems } \\
\hline & & F-value & p-value & \%change & F-value & p-value & \%change & F-value & p-value & \%change \\
\hline LDI & Pre-Post 1 & $4.29^{\mathrm{a}}$ & 0.04 & -13.30 & 0.87 & 0.35 & c & $3.09^{b}$ & 0.08 & -3.60 \\
\hline LDI & Post 1 - Post 2 & 0.09 & 0.77 & c & $6.7^{a}$ & 0.009 & 22.23 & $12.43^{\mathrm{a}}$ & 0.0005 & 14.30 \\
\hline OR & Pre - Post 1 & $5.7^{\mathrm{a}}$ & 0.01 & -5.20 & 0.06 & 0.8 & c & $12.12^{\mathrm{a}}$ & 0.0007 & -18 \\
\hline OR & Post 1 - Post 2 & 1.17 & 0.28 & c & $12.92^{\mathrm{a}}$ & 0.0007 & 22.10 & $3.43^{b}$ & 0.07 & 4 \\
\hline $\mathrm{PC}$ & Pre - Post 1 & $7.83^{\mathrm{a}}$ & 0.006 & 6.90 & 0.7 & 0.4 & c & $11.86^{\mathrm{a}}$ & 0.0008 & 15 \\
\hline $\mathrm{PC}$ & Post 1 - Post 2 . & 0.11 & 0.73 & c & $8.16^{a}$ & 0.006 & 10 & $14.49^{\mathrm{a}}$ & 0.0004 & 24 \\
\hline RPVM & Pre - Post 1 & $26.38^{a}$ & 0.0001 & -22.70 & 0.73 & 0.39 & c & 0.87 & 0.35 & c \\
\hline RPVM & Post 1 - Post 2 & 1.88 & 0.17 & c & 0.1 & 0.92 & c & 2.2 & 0.14 & c \\
\hline
\end{tabular}




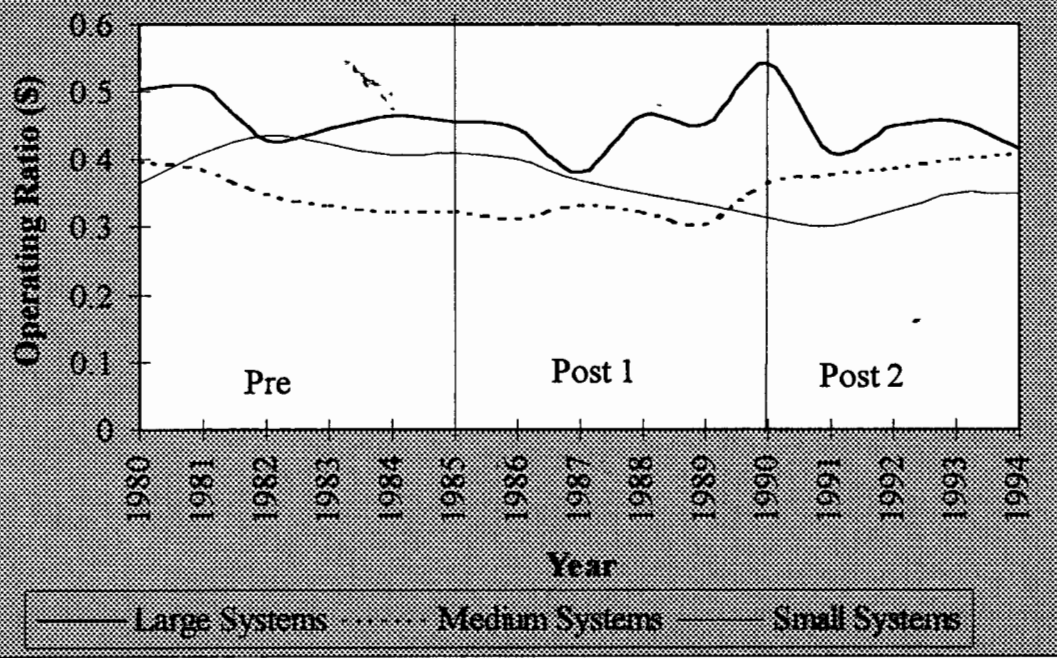

Figure 1. Trends in operating ratio for systems of different size.

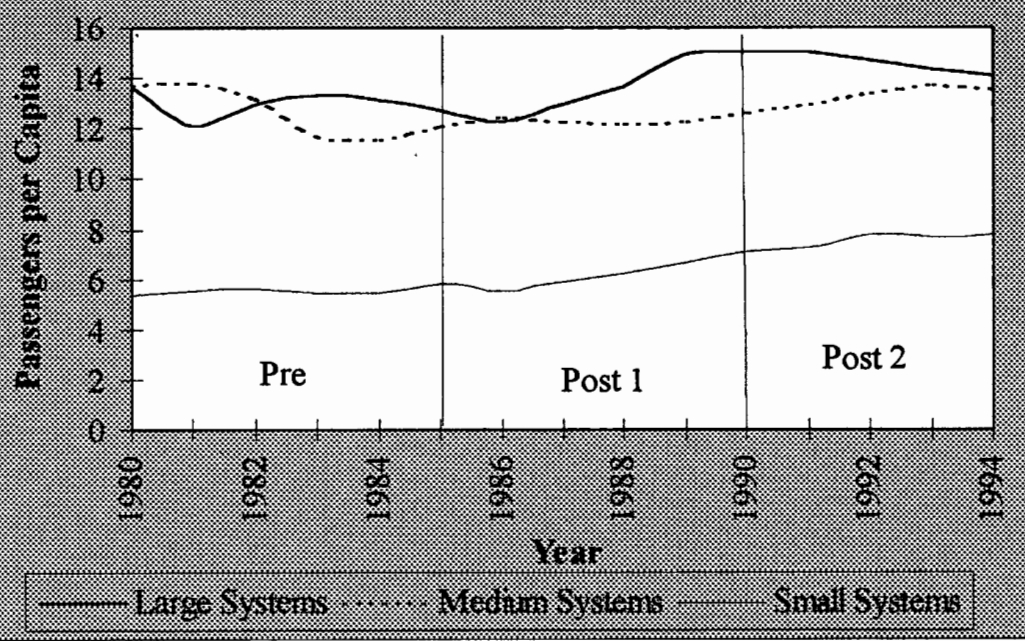

Figure 2. Trends in passengers per capita for systems of different size. 
the small systems the value of this indicator was increased in the Post 1 period. In the Post 1-Post 2 period comparisons, the F-statistic values indicate that, for the medium and small systems, there was a statistically-significant positive change.

The passengers per revenue vehicle miles mean comparison (Figure 3), demonstrated a significant change only for the large systems between the Pre and Post 1 periods. For the Post 1-Post 2 comparison, there were no significant changes in the values of the indicators for any system group. The LDI was significantly decreased for both large and small systems between the Pre and the Post 1 periods, while it significantly increased for the medium and small systems between the Post 1 and Post 2 periods (Figures 4, 5, and 6).

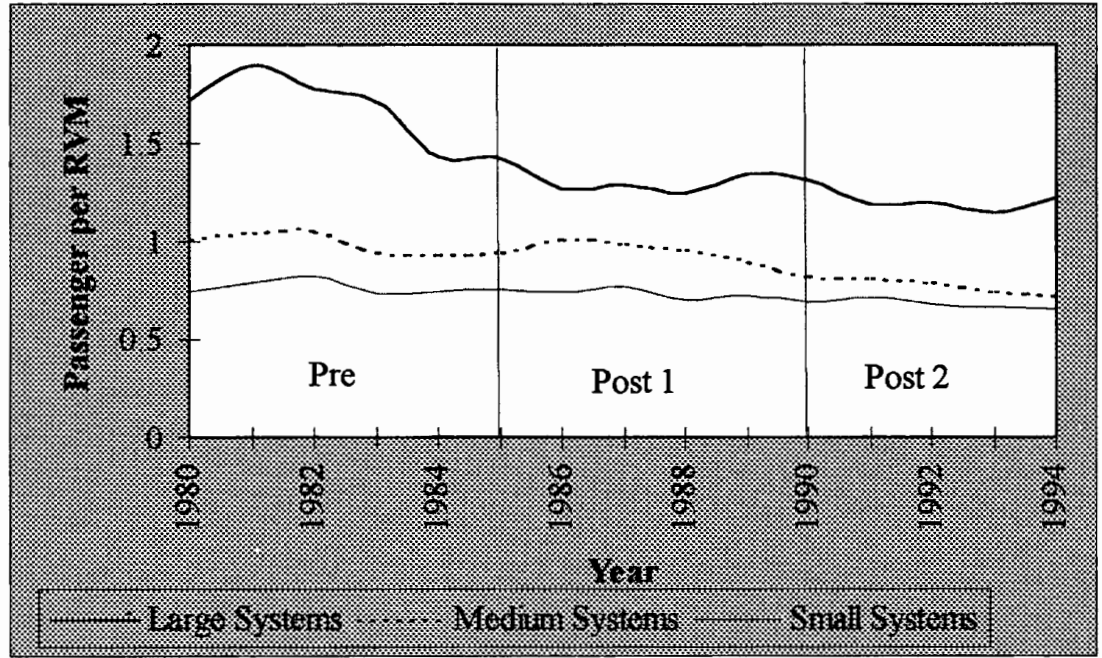

Figure 3. Trends in passengers per rèvenue vehicle mile for systems of different size. 


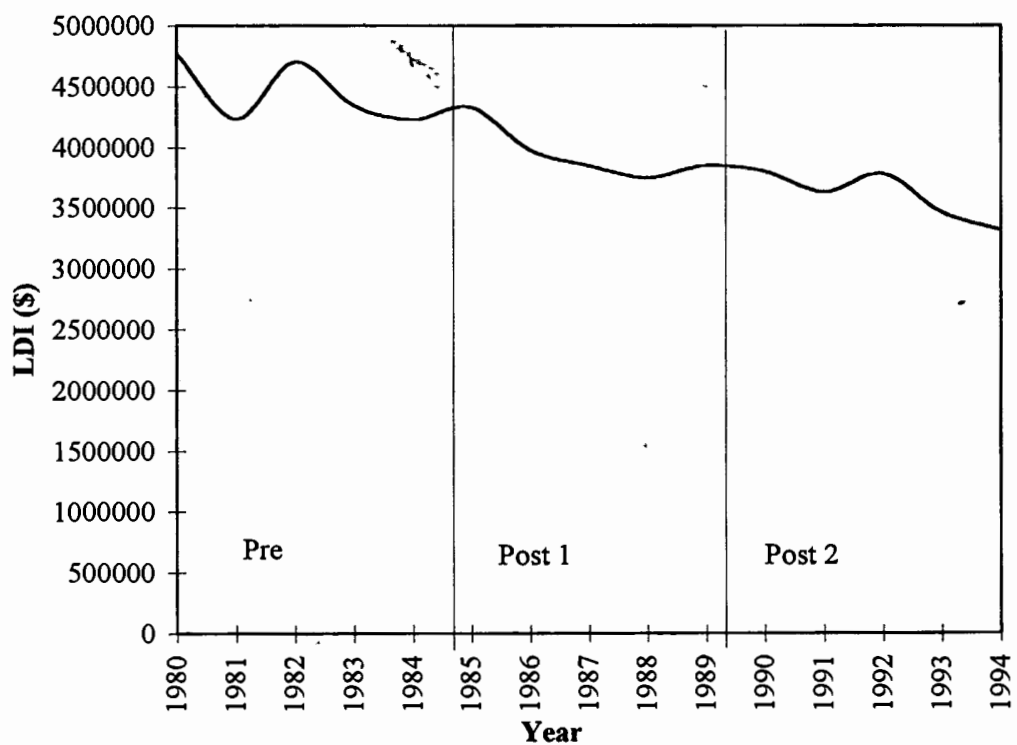

Figure 4. Trends in locally-derived income-large systems.

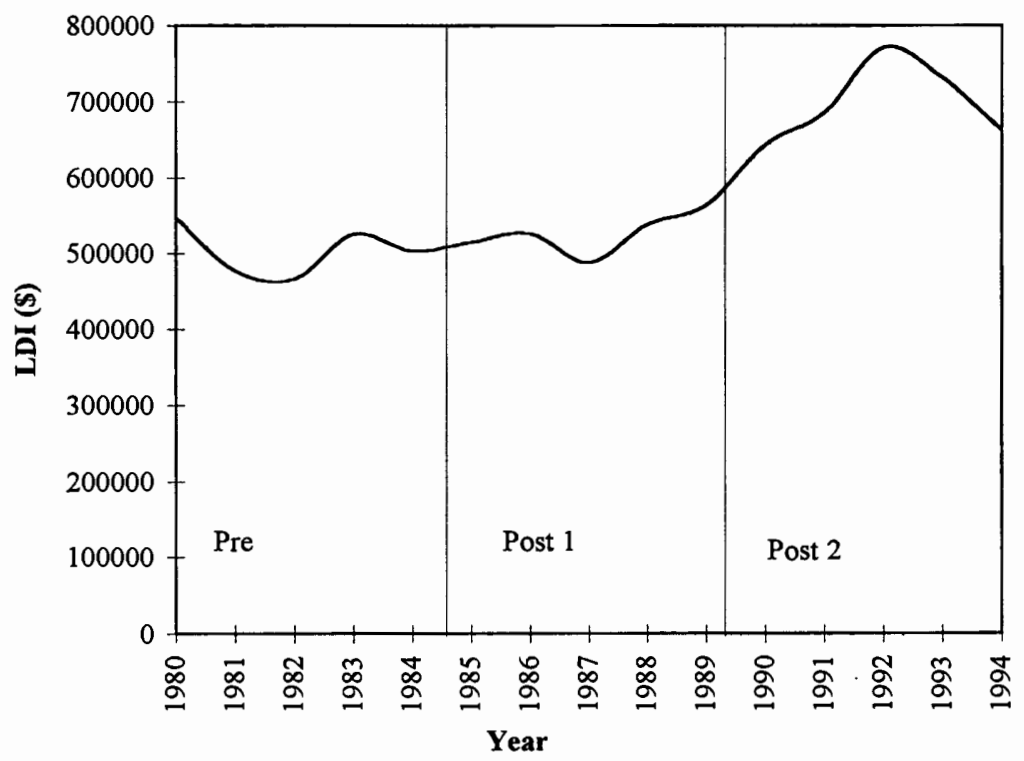

Figure 5. Trends in locally-derived income-medium systems. 


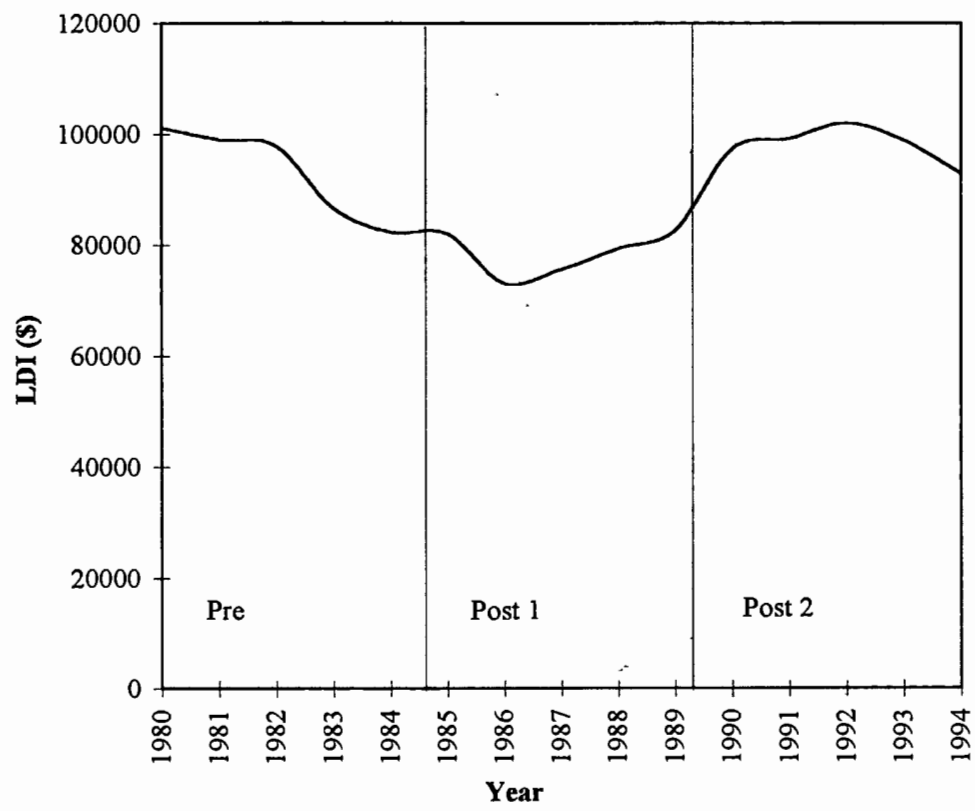

Figure 6. Trends in locally-derived income-small systems.

\section{Interpretation of Results}

\section{By Indicator}

The statistical analysis performed in this paper indicates that the OR and the LDI, representing system self-sufficiency and local commitment to public transportation, were originally negatively affected by the performance-based subsidy allocation procedure. While the statistical analysis does show that these performance measures were negatively affected by the allocation procedure, Figures 1 , 4,5 , and 6 seem to show that these indicators were on negative trends that were not impacted until some later time. Furthermore, given the one-year lag between the data and allocation years, the Post 1-Post 2 comparison indicates that, given some time for systems to adapt to the new procedure, the performance-based subsidy allocation eventually raised the OR and the LDI for the medium and small systems. It is interesting to notice that the OR, which captures the part of revenues absorbed by operating costs, and the $\mathrm{LDI}$, which mirrors the pure change in operating revenues, have realized the same changes in sign; that is, in both 
cases the large and small systems were originally negatively affected by the change in allocation procedure, while exentually the medium and small systems realized a significant increase in both $\mathrm{OR}$ and LDI.

The passengers per capita indicator, which captures transit system effectiveness and patronage, was positively affected by the change in subsidy allocation across the board. The large and small systems were immediately affected by the change in subsidy allocation, increasing their passengers per capita by approximately 7 percent for large and 15 percent for small systems. In the next phase (Post 1-Post 2), the medium and small systems were positively affected by realizing an increase of 10 percent and 24 percent, respectively, in their value of passengers per capita indicator. It is very important to note that system effectiveness and reliability were positively affected for all system sizes.

The passengers per revenue vehicle mile indicator, which captures service efficiency and utilization, was significantly affected only in the first period, and only for the large systems. The passengers per revenue vehicle mile indicator for large systems decreased, on the average, 23 percent between the Pre and Post 1 periods. In all other cases, the values of this indicator for all the systems were left unchanged by the new subsidy allocation procedure.

\section{By System Size}

What is apparent from the statistical analysis performed in the previous section is that the small systems were the ones most dramatically affected by the switch in subsidy allocation procedure. They were affected in a positive manner, in terms of both self-reliance and local commitment, as well as patronage and effectiveness. The OR and LDI values for the small systems decreased in the first period after the change in allocation procedure, but eventually recovered fully (in the case of LDI) or are in the process of recovering to their original values for the OR indicator. It is also interesting to note that the effectiveness of small systems (measured with the passengers per capita indicator) was aided tremendously by the change in allocation procedure, increasing by 15 percent in the Pre-Post 1 period, and by 24 percent in the Post 1-Post 2 period.

The medium systems were also positively affected by the switch in allocation procedure. Their self-reliance and local commitment improved by approxi- 
mately 22 percent (same increase for both the OR and LDI values), their patronage and effectiveness increased by 10 percent, and their efficiency was left unchanged. The large systems were the only ones whose performance did not respond favorably to the objectives of the subsidy allocation procedure. The LDI for the areas served by the systems and the OR decreased in the first period by approximately 13 percent and 5 percent, respectively. Their efficiency decreased by 22 percent, and only their effectiveness improved, by approximately 7 percent. It should be noted, however, that from Figure 3 it can be inferred that the large systems already had been realizing a significant decrease in their passengers per revenue vehicle mile levels before the change in allocation procedure was instituted. That is, this decrease could be a general change in large system efficiency and not a direct result of the change in allocation procedure.

\section{By Period}

Large systems were immediately affected by the change in state subsidy allocation procedure in a negative way, with the exception of effectiveness. This category of systems showed no statistically-significant change in the second period (Post 2) after the change:

Medium systems, which were positively affected by the change in terms of both self-reliance and effectiveness, required some time to adjust to, and realize improvements from, the change in allocation procedure. The values for the indicators of the medium systems showed an increase of 22 percent for the OR and LDI indicators and 13 percent for the passengers per capita indicators in the second period (Post 2).

The small systems, which by and large were positively affected by the change, realized large positive effects in the second period after the change (Post 2). In the first period after the change, the patronage and effectiveness of the small systems was increased, while their self-reliance decreased. Again, the effectiveness of these systems was left unchanged in both periods.

\section{Conclusions}

Although the findings of the statistical analysis utilized in this paper vary depending on system size, type of performance indicator (self-reliance or effec- 
tiveness or service utilization), and time period, they support the same conclusion. Performance-based subsidy allocation has helped transit systems of all sizes to largely improve their accessibility and has helped medium- and small-sized transit systems improve their self-reliance and local support. Service efficiency has, by and large, been unaffected by this change. The large systems have not responded in the same way as the smaller systems, but it should be noted that large systems are the ones whose percentage contribution of state subsidy to total subsidy is the lowest (Table 1). The largest part of subsidy for the large systems comes from the population-based federal subsidy program, which does not directly encourage system efficiency or innovation. The size of the state subsidy does not provide sufficient motivation for large systems to change.

It has been the stated policy of the INDOT to encourage increased local financial commitment to transit. Therefore, as state and federal funds become increasingly limited, only those systems that indicate a strong local commitment may be able to remain in operation. It can be expected that, for some systems, the local assistance will increase in the case of a severe federal cut. On the other hand, some systems may not receive any additional local assistance, nor can they remain viable through service-cut and fare increases. Those systems, most likely, will not be able to continue operating and will be candidates for elimination from the state assistance program. The performance-based subsidy allocation procedure can be of assistance in determining which systems are viable (in terms of seeking innovative financing methods and demonstrating strong local commitment to public transit) and should remain in service, and which are not.

As suggested in this study, tightly-controlled and performance-based subsidy allocations can have a positive effect, at least in terms of effectiveness and self-reliance, on public transit systems. A good and promising way to subsidize transit systems is to tie both federal and state assistance to performance indicators. By penalizing inefficient systems and rewarding efficient ones, such an arrangement would at least reduce the incentive for unwarranted cost escalation (Pucher 1983). This would be a sharp contrast to the current situation in which the greater the cost generated, the greater the subsidy received. Although it is 
impossible to detach inefficiency from government subsidies, a performancebased allocation could be a step in the right direction.

\section{References}

Altshuler, A., J. Womack, and J. Pucher. 1981. The Urban Transportation System: Politics and Policy Innovation. Cambridge, MA: M.I.T. Press.

Anderson, S. H. 1983. The Effect of Government Ownership and Subsidy on Performance: Evidence from the Bus Transit Industry. Transportation Research A 17A, No. 3: $191-200$.

Bly, P. H., and R. H. Oldfield. 1986. The Effects of Public Transport Subsidies on Demand and Supply. Transportation Research A 20A, No. 6: 415-427.

Bly, P. H., F. V. Webster, and S. Pounds. 1980. Effects of Subsidies on Public Transport. Transportation 9: 311-331.

Bonnell, J. 1981. Transit's Growing Fiscal Crisis. Traffic Quarterly 35, No. 4: 541-556. Caves, D. W., and L. R. Christensen. 1988. The Importance of Economies of Scale, Capacity Utilization, and Density in Explaining Inter-Industry Differences in Productivity Growth. The Logistic and Transportation Review 24 (1): 3-32.

Cervero, R. 1984. Cost and Performance Impacts of Transit Subsidy Programs. Transportation Research A 18A, No. 5/6: 407-413.

Cervero, R. 1986. Examining the Performance Impacts of Transit Operating Subsidies. ASCE Journal of Transportation Engineering 115, No. 5, 467-480.

Crider, D., and K. C. Sinha. 1982. Use of Performance Indicators in Transit Subsidy Allocation: A Case Study. Presented at the 61st Transportation Research Board meeting, Washington, D.C.

Fielding, G. L., R. E. Glauthier, and C. A. Lave. 1978. Performance Indicators for Transit Management. Transportation 7: 365-379.

Hammer, A. 1976. The Selling of Rapid Rail Transit. Lexington, MA: Lexington-Heath Books.

Hilton, G. W. 1974. Federal Transit Subsidies. American Enterprise Institute, Washington, D.C.

Lamare, J. L. 1980. Can Transit Assistance Policy Procedure Improve Industry Performance? Transit Journal 6, No. 4: 3-12.

Meyer, J., and J. Gomez-Ibanez. 1981. Autos, Transit, and Cities. Cambridge, MA: Harvard University Press. 
Meyer, J., J. Kain, and M. Wohl. 1965. The Urban Transportation Problem. Cambridge, MA: Harvard University Press.

Miller, J. 1980. The Use of Performanice-based Methodologies for the Allocation of Transit Operating Funds. Traffic Quarterly 34, No. 4: 555-574.

Obeng, K., W. K. Talley, and C. Coldburn. 1995. The Effects of Subsidies on Public Transit Long-Run Costs. Transportation Research Forum.

Orski, K. C. 1985. Redesigning Local Transportation Services, in: Lave, C.(ed.), Public Transit. Cambridge, MA: Ballinger Publishing Co.

Pickrell, D. H. 1985. Rising Deficits and the Uses of Transit Subsidies in the United States. Journal of Transport Economics and Policy: 281-298.

Pucher, J. 1985. Urban Public Transport Subsidies in Western Europe and North America.

Transportation Quarterly, Vol. 42, No. 3: 377-402.

Pucher, J. 1995. Urban Passenger Transport in the United States and Europe: A Comparative Analysis of Public Policies, Part 2: Public Transport, Overall Comparisons and Recommendations. Transport Reviews, Vol. 15, No. 3: 211-227.

Pucher, J., and A. Markstedt. 1983. Consequences of Public Ownership and Subsidies for Mass Transit: Evidence from Case Studies and Regression Analysis. Transportation 11: 323-345.

Pucher, J., A. Markstedt, and I. Hirschman. 1983. Impacts of Subsidies on the Costs of Urban Public Transport. Journal of Transport Economics and Policy: 155-176.

Sinha, K. C., E. A. Sharaf, D. T. Barnum, M. Saito, H. S. Tsay, and.J. D. Riverson. 1985. Development of an Approach for the Allocation of the Public Mass Transportation Fund in Indiana, Final Report. Purdue University, CE-TRA-85-3, West Lafayette, IN.

Sinha, K. C., M. J. Doherty, R. Muncey, and J. D. Riverson. 1986. Evaluation of State Transit Subsidy Policies in Response to Reduction in Federal Assistance, Final Report. Purdue University, CE-TRA-86-1, West Lafayette, IN.

U.S. House of Representatives. 1981. The Financial and Productivity Problems of Urban Public Transportation. Committee on Transportation and Public Works, Washington, D.C.

Webber, M. 1976. The BART Experience: What Have We Learned? The Public Interest 45, Fall: 79-108. 


\section{About the Authors}

DR. Matthew G. Karlaftis is Visiting Assistant Professor in the Department of Transportation and Urban Engineering in the School of Civil Engineering at Purdue University in Indiana. His research interests include transportation economics, the use of market equilibrium models for transportation system efficiency and productivity measurement, traffic safety, and ITS. DR. Kumares C. SinHa is Professor and Head of Transportation and Urban Engineering in the School of Civil Engineering at Purdue University in Indiana. He is an internationally-recognized expert in transport planning management and has done extensive research in transit performance and subsidy analysis. He has authored more than 250 technical publications and is currently the Editor-in-Chief of the Journal of Transportation Engineering. 
in. 